\title{
THE CO-REGULATORY SCHEME FOR INTERNET CONTENT REGULATION: OPERATIONAL EFFECTIVENESS
}

\author{
Geoffrey A Sandy \\ School of Information Systems \\ Faculty of Business and Law \\ Victoria University, Melbourne, Australia \\ E-mail: Geoff.Sandy@,vu.edu.au
}

\begin{abstract}
The debate about the likely effectives of a Scheme to regulate the access to certain Internet content during the hearings of the Select Senate Select Committee and during the parliamentary debates was characterized by a great diversity of opinion. This paper describes these opinions and then examines the claims made about the operational effectiveness of the Co-Regulatory Scheme for Internet Content Regulation since its inception on 1 January 2000.
\end{abstract}

Keywords Internet Content Regulation, Co-Regulatory Scheme, Online Services Bill, Censorship

\section{INTRODUCTION}

Recently, the Department of Communications Information Technology and the Arts published a review of the operation of Schedule 5 to the Broadcasting Services Act (Commonwealth of Australia 2002). This refers to the Co Regulatory Scheme for Internet Content Regulation that became operational on 1 January 2000. The purpose of the Scheme is to establish a framework for the regulation of the content of online services.). Specifically, the Scheme seeks to:

1. provide a means of addressing complaints about certain internet content

2. restrict access to certain internet content that is likely to cause offence to a reasonable adult

3. protect children from exposure to internet content that is unsuitable for them

In a relatively open society like Australia all political parties claim to support the principle that adults should be able to read, hear and see what they want. None would consider this as an absolute right to "freedom of expression". It is how this is interpreted that gives rise to different views about the justifiable degree of government censorship. Equally all would wish to protect children from unsuitable material but differ as to how this is to be defined, and as to the proper role of the Government in this regard. The Bill was prepared by the ruling conservative coalition but was opposed in part or whole by the opposition parties.

This paper discusses the effectiveness of the Scheme in terms of its specific objectives after two and half years of operation. It identifies the main arguments about its likely effectiveness of those who supported or opposed the Bill at the time of its preparation and passing through the parliament. It then examines the claims made about its operational effectiveness since that time. It does not address the existing or proposed State or Territory legislation regulating internet content.

The primary source documents used for this research are:

1. The Official Committee Hansard of the hearings from the submitters on the Broadcasting Services Amendment (Online Services) Bill 1999 by the Senate Select Committee on Information Technologies

2. Senate Hansard of the second reading of the Bill

3. House Hansard of the second reading of the Bill

4. The Broadcasting Services Amendment (Online Services) Bill 1999

5. Department of Communications, Information Technology and the Arts, Bi-Annual Reports of the Scheme

6. Official Media Releases

Throughout the paper reference is made to (1) above as the "hearings", (2) and (3) as the "debates" and (4) as the Bill. The abbreviated in-text citation used throughout for (1) is "SSC" for Senate Select Committee, (2) is "SH" for Senate Hansard and (3) is "HH" for House Hansard. Full details are provided in the references section. Acknowledgement is made of the reliance on the work of Electronic Frontiers Australia (EFA). EFA is the premier civil liberties group regarding the internet in Australia. Its views are representative of those opposed to the Bill and those who claim the Scheme is ineffective. 


\section{PROVIDING A MEANS OF ADDRESSING COMPLAINTS}

A specific objective of the Bill is to provide a means of addressing complaints by Australian residents or a body corporate that carries on activities in Australia about certain internet content. On receiving a complaint about internet material the ABA can require an Internet Service Provider (ISP) to take down $\mathrm{X}$ rated or refused classification material (RC) hosted onshore, and to take all reasonable steps to prevent access to $\mathrm{X}$ rated or RC material hosted offshore. In respect to restricted (R) classified onshore content the ABA must be satisfied that restricted access arrangements are in place. No proposal is made in respect to offshore $\mathrm{R}$ classified material. The Bill expressly specifies time frames for the take down process and penalties for non compliance.

Australia uses a classification system to determine the degree of censorship that is to be applied to a variety of offline media that includes films, videotapes, publications and video games. The Classification Board of the Office of Film and Literature Classification (OLFC) undertake the classification. The State and Territory Governments also use this although some adopt a more rigorous interpretation. Classification decisions apply criteria that are part of the National Classification Code. The most important "test" that determines a particular classification is the concept of a "reasonable adult". Such a person is defined officially as "possessing common sense and an open mind, and able to balance opinion with generally accepted community standards" (OLFC 1999b).

The Bill envisaged the establishment of a community advisory body on internet content now known as NetAlert. In a media release Minister Alston (1999) said that "NetAlert will be responsible for researching new access management technologies and running national awareness campaigns to promote a safer internet for young people". He saw NetAlert as "an additional measure that will play an important role by empowering parents to take control of the internet so that they can feel confident about their children going online".

The supporters of the Bill claimed the legislation was in response to a major concern expressed by the community about internet pornography (SH 5218; HH 6907). During the debates the coalition claimed the Bill had attracted little or no criticism from the public (SH 5218) and Minister Alston asserted that internet pornography is a major social problem for Australia. Indeed, some coalition members believe the internet is awash with pornography with the claim that it constitutes $60 \%$ of its content (SSC49; 73). Internet industry representatives at the hearings reacted with incredulity to this claim (SSC 49; 73).

No comprehensive study on community attitudes to internet pornography has been conducted in Australia. Both supporters and opponents of the Bill provide anecdotal evidence to support their case (SH 5210; 5212). What empirical evidence exists suggests that internet pornography is not a major concern (SSC 260ff; 297 299). However, few Australian would support child pornography and Minister Alston (2001), in a media report cites a recent survey by AustraliaSCAN that found 97\% of Australians are opposed to child pornography. It can be argued that the establishment of a formal mechanism to process complaints and publicizing that fact can act as a self-fulfilling prophecy. In other words the very act of establishing a mechanism to deal with a perceived social concern may create the social concern. Sensational press stories about internet porn can also act to "manufacture" concern when it is not strong.

\section{RESTRICT ACCESS BY ADULTS TO OFFENSIVE MATERIAL}

The classic libertarian position is to treat freedom of speech as indispensable to the open society. If the government wishes to censor some type of speech, like pornography, then the onus of proof of demonstrable harm rests with the government. State intervention to censor pornography without empirically proven evidence of social harm is an illegitimate exercise of state power in an open society. During the hearings and the debates offensive and unsuitable material was almost invariable equated with pornography. Surprisingly little was said about equating harm of the "reasonable adult" with feelings of being offended by an image and/or text. This is central to the governments system of censorship of any media. Vital to a view on pornographic harm is the meaning and power of the pornographic image (Sandy 2001). One view is that the pornographic image is a master text to practices it portrays. It does represent real (bad) attitudes and desires, and, it teaches the consumer these attitudes, and to expect to recreate these practices in reality. As indicated previously there is little empirical support for this view. Many supporters of the Bill accepted this view (SSC 108; SH 5212-5213).

The opposing view is that the pornographic image is a signifying system and a fantasy scenario. What is portrayed is not the object of desire but a scenario in which certain wishes are presented. This may involve scenarios that are illegal as acts. Fantasy is clearly a separate realm from reality and cannot be taken at face value. Opponents of the Bill tended to make this distinction an claimed the Bill would violate the freedom of an adults (SH 5199;5207;5213). The representative of the Australian Computer Society, for instance, spoke for many when he argued that the internet should remain an adult medium and should not be transformed into a media suitable only for children (SSC 72). This he claimed would be the effect of the legislation. 
Supporters of the Bill asserted it did not suppress free speech (SCC150; HH 6907; SH 5219). Further, the coalition countered that the internet warranted no special treatment in regards to government regulation compared to the other media ( $\mathrm{SH} 5219$; HH 6970). What is censored offline is now to be censored online. However, this begs the question about whether censorship of other media is justified

Most research studies on pornographic harm are for media other than the internet. Australia lacks empirical research in this area. As is common for any contentious area each group holding different views claim the research findings support their particular view. Pornographic harm is no exception. Sandy (2001) summarized these studies and they suggest there is no causative link between sexually explicit material and acts of violence (non consensual) or in a change of male attitudes (for the worse) towards women. This is whether the sexually explicit image is accompanied by violence or not. It appears that there is little empirical support to justify censorship of pornography in an open society on the grounds of it being harmful to adults. If this is accepted then this applies to all media and not just the internet.

In regard to minors and pornographic harm there are no reported studies for obvious ethical reasons. In the case of images of pedophilia or images of incest with minors it is widely agreed that these be illegal because it is assumed that production of such images involve non-consensual acts. Recently, the Supreme Court of the United States ruled that legislation that made morphed child pornography images illegal was contrary to the First Amendment.

EFA claim that the Scheme is one component of a wider strategy by the coalition and other conservative forces to curtail adult freedoms. The "evidence" cited includes:

1. tighter regulation that goes beyond pornography to adult themes, especially in regard to films (EFA 1999)

2. failure to approve a change from $X$ rated videos to Non Violent Erotica (EFA 2000c)

3. more restrictive treatment of computer games (OLFC 1999a)

4. standardisation (more restrictive) of classification criteria used by the OLFC (EFA 2000b)

5. proposed "excessive and overboard" Cybercrime Bill 2001 (EFA 2001a)

6. "tougher" Telecommunications (Interception) Legislation Amendment (EFA 2001b)

7. proposed "profoundly flawed" New South Wales Internet Censorship Bill 2001 (EFA 2002a)

8. proposed "profoundly flawed" South Australian Net Censorship Bill 2000-2001 (2002b)

All of these examples pre-date September 11. Libertarians are concerned that we now operate in a climate that is more conducive to legislating away adult freedoms.

\section{PROTECTION OF CHILDREN}

The issue of protection of children from unsuitable material was a dominant one during the hearings and debates. It remains the key issue in discussions about the operational effectiveness of the Scheme. All parties agree that both parents (including teachers, librarians etc) and the government have a role in protection of children from unsuitable internet material. The main disagreement concerns the degree of freedom left to the parent to determine what material the child consumes.

Supporters of the Bill argued that the Government must be pro-active in doing all it could to assist parents and guardians in undertaking their parental responsibility. The coalition members argued that the Scheme would support parents who lack the technical knowledge necessary to properly supervise their children's access to the internet (SSC 51; SH 5219; HH 7977). Much was made by them of portraying children as more technically competent than their parents, and because of this, are able to deceive their parents about their internet use. Implicit in the arguments of some supporters of the Bill was that it would counter irresponsible parents who did not properly supervise their children's internet access (SSC 51; 157-158; SH 5219; 5212). The Bill was considered necessary to protect children from their own (irresponsible) parents.

Coalition members at the hearings adopted a similar view towards library staff in regards to supervision of internet access by children in libraries. They suggested that library staff are too busy to be monitor breaches of policy, and given the tenor of questioning an implicit suggestion that the library policy on this matter borders on the irresponsible (SSC 192ff; 103).

Originally the Government believed that unsuitable material could be successfully blocked at the ISP or "backbone" provider level. Those opposed to the Bill argued that the best place to block content is at the receiver and not the ISP or backbone provider (SSC 151ff; 243ff). The findings of a report by the Commonwealth Scientific and Industrial Research Organisation (CSIRO 1999) were given prominence in the hearings and debates. It was treated as authoritative by both sides. The report considered blocking access at the ISP or backbone provider level to be largely ineffective. Instead it recommended the use of filtering 
software by internet users. It evaluated the effectiveness of filter products and commented on their deficiencies.

The coalition acknowledged the deficiencies of the filter products but looked forward to a future where technology had developed to such a state that it would make the Bill more enforceable (HH 7978). Until then the coalition responded by stating "the fact that some aspects of the bill are in the opinion of some in the industry, unlikely to succeed is not argument enough, for the government to ignore this issue and to allow the internet to go unchecked as a conduit to the world's unsavory material for our children" (HH 7978). More recently the CSIRO (2001) has evaluated the effectiveness of 14 internet filtering software on behalf of the ABA. It found that they vary considerably in their effectiveness in blocking targeted material.

A common argument made by those opposed to the Bill was that not only is the blocking software ineffective in protecting minors but the charge that the government is deceiving parents into believing the technology is trustworthy (HH 7970ff; SSC 257-258; 104). Thus, parents are "lulled into a false sense of security" (SSC 245) and therefore "the Bill could do more harm than good" (SSC 63). Further, it was argued that the government by putting its faith in software that does not work results in a lost opportunity to educate and empower parents to take responsibility for supervision of the internet by their children (SSC 6914).

The strongest claim about the likely ineffectiveness of the Scheme was by industry spokespersons at the hearings (SCC 63ff; 127ff) and of others in the debates (HH 7970; SH 5136). They argued that the legislation will not work because over 90 per cent of the content is hosted offshore. The supporters of the Bill were also reminded of the ease with which domestic sites could move offshore to escape enforcement (HH 6913).

Some opposition members (SH 5199; 5210) and submitters to the hearings (SSC 48-49; 70) pointed out that the Bill is not needed because the existing laws, especially the Crimes Act, are adequate to deal with illegal activity online. An industry spokesperson at the hearings succinctly put it "as far as we know there are no illegal activities that become less illegal on the internet" (SSC 209). However, the hearings were told that some uncertainty exists as to whether the Crimes Act does cover the internet (SCC 123). The coalition indicated it would legislate to rid the Act of any uncertainty (HH 6907).

Opponents of the Bill stressed during the hearings and debates (SSC 244; 262ff;SH 5198ff) that a society, like Australia, is composed of many communities of widely differing standards in relation to sexuality, gender relations and sexual expression. One of Australia's greatest assets is a social structure that is highly pluralistic. In reality, the "test" of the "reasonable adult" results in the majoritian norm being forced on all communities. In an open society like Australia, speech that is deemed illegal or restricted should depend on "proving" its demonstrable harm. In the absence of this mere offensiveness to a group is no justification for censorship by the state.

\section{OPERATIONAL EFFECTIVENESS OF THE CO-REGULATORY SCHEME}

In an attempt to gather evidence of the Scheme's ineffectiveness EFA in February 2000 lodged a FOI with the ABA seeking material banned and not banned under the Scheme. It was seeking evidence to "prove our point that the system put in place will not work and cannot ever work. The whole system's basic concept is flawed because most content on the net is hosted outside Australia so there is nothing the Government can do about it"(EFA 2000a). Six months later some documents were released by the ABA. EFA accused the ABA of a "net cover-up" (Jackson 2000). After examination of the released documents EFA (2000a) made the following claims about the operational effectiveness of the Scheme:

1. the blacked out URLs were not only of banned pages but for papers not banned.

2. discrepancies exist between the information released and the ABA's first quarter report issued in April (ABA 2000) and Minister Alston's first bi-annual report on the Scheme tabled in September (Commonwealth of Australia 2000).

3. the ABA had gone beyond its legislature remit and made a value judgment as to what may harm if the URLs for certain non-prohibited content are released.

4. the ABA has acted on and prohibited content as a result of complaints received from non-Australian residents.

In media releases Minister Alston (2001a; 2000) claims the internet is safer for all Australians because of the work of the ABA of continual removal of illegal and highly offensive material on the internet particularly child pornography sites. He refers to the second and third bi-annual reports on the Scheme (Commonwealth of Australia 2001; 2002). Referring to the second bi-annual report he indicates that the ABA completed 221 investigations of which 139 resulted in a location of prohibited or potentially prohibited content. He states "this represents a 49 per cent increase in the number of completed investigations which located such material in the first six-month period and demonstrates the Scheme's continued effectiveness in addressing public 
concerns regarding the nature and accessibility of some Internet content'. He believes "Australian families will welcome the continued removal by the Online Content Regulatory Scheme of illegal and highly offensive material on the Internet, particularly child pornography sites". He also discusses the work of Net Alert in assisting industry to reach full compliance through the development of an information manual and a series of national industry compliance seminars targeting smaller ISPs. In addition he states that NetAlert and the ABA are working on research and community education initiatives. Specifically, NetAlert' advisory services, tollfree national help line, information kit and website are mentioned. Similar reference is made in the third biannual report.

EFA (2001c) and others claim that the Scheme has failed to achieve its objectives. First, the ABA has gone out of its way to portray the reported figures in a way that overstates the apparent effectiveness of the Scheme. The ABA's Internet Content Complaint Form clearly states you can only complain about one item of internet content in each complaint form. However, the ABA in the second bi-annual report indicates 67 "items" of prohibited content from 6 Australian sites. In contrast 136 items of prohibited content were reported in respect of the 133 overseas sites. The third bi-annual report indicates that the ABA issued 8 take-down notices to Australian hosts covering 37 items of prohibited content. EFA believes the ABA is ramping up the "item count" in order to make the figures look respectable in relation to Australian content.

Second, of the 67 items of prohibited content 45 items (child pornography) from 6 Australian sites were referred to the State/ Territory Police. Similarly, of the 37 items 23 that are child pornography were also referred. It would appear no successful prosecutions have been undertaken. EFA claim most of these complaints relate to newsgroups. The Australia Institute (Flood and Hamilton 2003) believe that "not only the regulation of pornography on the Internet is manifestly failing but the regulatory authorities themselves appear to have lost sight of their functions". It claims the ABA seems more concerned to promote the use of the Internet than to protect children from its dangers.

Third, Minister Alston is criticized for "misleading political rhetoric" that grossly overstates the impact of the Scheme. This lulls Australian parents into a false sense of security. The claims made by him play on the emotive impact of the child pornography bogieman, without any supporting information about prosecutions of Australians for publishing such material.

Fourth, EFA estimates that the total cost of the Scheme for the first 12 months of operation is $\$ 2.5 \mathrm{~m}$. and suggests the benefits are not cost effective. It suggests the impact in Australia has been the cancellation of a number of newsgroups and a few adult Australian web sites forced offshore (Forbes 1999). Further, it is claimed that NetAlert's activities are equally questionable in terms of outcome.

Fifth, EFA suggests that by encouraging Australian citizens to report child abuse material to the ABA, the process places complainants at risk of committing a criminal offence. The mere awareness of the existence of such material implies that it has been downloaded into the complainant's computer. It is noted that there is nothing in the Bill that grants immunity from liability for persons reporting illegal content.

Sixth, it is claimed that the ABA fails to disclose what content has been removed and why. This is different from the treatment of offline content (Taggart 2002). David Flint, Chairman of the ABA counters by stating that the internet is different from the offline media and believes that making child pornography URLs public will jeopardize the policing and legal processes (Taggart 2002). Recently, the Administrative Appeals Tribunal (2002) ruled against EFA and in favour of the ABA.

Seventh, Minister Alston (2001b) claims that the success of the Scheme will lead to an uptake of the new technology by families and this in turn will drive the growth of the new economy in Australia. However, McAuliffe (2001) points out that the latest Bureau of Statistics figures show the number on internet subscribers in Australia rose by 3.9 million at the end of the December quarter but there were 7,000 fewer household internet accounts and decrease in 307,000 free internet accounts. The Bureau believes the decline is due to industry restructuring and ISPs going out of business.

\section{CONCLUSION}

The key test regarding the operational effectiveness of the Co-Regulatory Scheme is whether it has lead to significantly greater protection of children from unsuitable internet content. Supporters of the Scheme claim that this is the case and is evidenced by:

1. the issue of take-down notices and referrals of illegal material (child pornography) to the federal police of sites hosted overseas and to the state/ territory police of sites hosted in Australia.

2. the work of NetAlert on research for example the technical evaluation of filters by the CSIRO

3. the work of NetAlert community education initiatives for example promotion of the Australian Families Guide to the Internet web site and presentations at various conferences. 
Opponents of the Scheme claim the Scheme is ineffective principally because overwhelmingly unsuitable content is hosted overseas and all the Government can do if it is illegal is to refer it to the federal police. Australian sites referred to the state/ territory police are few and there is no evidence of any successful prosecutions in relation to these. Critics of the Scheme remain unconvinced the Scheme was necessary as such material was and is covered by the states/ territory's Crime Acts. Further they assert that parents may be lulled into a false sense of security believing the Scheme to be effective in protecting children when it is not.

At this stage the weight of evidence suggests the Scheme has not afforded children significantly greater protection against unsuitable internet content.

\section{REFERENCES}

Alston R (2000) A safer Internet for all Australians, Media Release, 19 May.

Alston R (2001a) Australia's safer Internet Media Release, 13 February.

Alston R (2001b) Growing Internet and Computer Use Media Release, 8 May.

Alston R (1999) Internet Content Advisory Scheme Announced, Media Release, 26 November.

Australian Broadcasting Authority (2000) Internet Content Complaints Scheme - The First 3 Months. http://www.aba.gov.au/about/public_relations/newrel_2000/27nr2000.htm date accessed 20 June 2000.

Commonwealth Administrative Appeals Tribunal (2002) Electronic Frontiers Australia Inc and Australian Broadcasting Authority, AATA 449 (12 June 2002).

Commonwealth of Australia (2002) A Review of the Operation of Schedule 5 to the Broadcasting Services Act 1992: Issues Paper, September.

Commonwealth of Australia (2002) Sixth-Month Report on Co-Regulatory Scheme for Internet Content Regulation January to June 2001 Department of Communications, Information Technology and the Arts, February

Commonwealth of Australia (2001) Sixth-Month Report on Co-Regulatory Scheme for Internet Content Regulation July to December 2000 Department of Communications, Information Technology and the Arts, April.

Commonwealth of Australia (2000) Sixth-Month Report on Co-Regulatory Scheme for Internet Content Regulation January to June 2000 Department of Communications, Information technology and the Arts, September.

Commonwealth of Australia (1999) Broadcasting Services Amendment (Online Services) Act 1999.

Commonwealth of Australia (1999) House Hansard: Broadcasting Services Amendment (Online Services) Bill 1999 - Second Reading, Canberra.

Commonwealth of Australia (1999) Official Committee Hansard: Senate Select Committee on Information Technologies - Broadcasting Services Amendment (Online Services) Bill 1999, Canberra.

Commonwealth of Australia (1999) Senate Hansard: Broadcasting Services Amendment (Online Services) Bill 1999 - Second Reading, Canberra.

Commonwealth Scientific and Industrial Research Organisation (1999) Blocking Content on the Internet: A Technical Perspective. Division of Mathematical and Information Sciences, June

Commonwealth Scientific and Industrial Research Organisation (2001) Effectiveness of Internet Filtering Software, Mathematical and Information Sciences, September.

Electronic Frontiers Australia (2002a) New South Wales Censorship Bill 2001. http://www. efa.org.au/Campaigsn/nswbill.html date accessed 28 March 2002.

Electronic Frontiers Australia (2002b) South Australian Net Censorship Bill 2000-2001 http://www.efa.org.au/Campaigns/sabill.html date accessed 28 arch 2002.

Electronic Frontiers Australia (2001a) Cybercrime Bill 2001 http://www.efa.org.au/Issues/Security/ date accessed 28 March 2002.

Electronic Frontiers Australia (20001b) On-line $\quad$ Surveillance http://www.efa.org.au/Issues/Privacy/surveillance.html date accessed 28 March 2002.

Electronic Frontiers Australia (2001c) Regulatory Failure: Australia's Internet Censorship Regime http://www.efa.org.au/Analysis/aba_analysis.html date accessed 26 October 2001.

Electronic Frontiers Australia (2000a) FOI Request on ABA Report on Documents Released/ Denied. http://www.efa.org.au/FOI/efa_foibarep1.html date accessed 9 September 2000.

Electronic Frontiers Australia (2000b) Proposed Changes to Classification/ Censorship Act http://www.efa.org.au/Issues/Censor/classifrev01.html date accessed 15 April 2002.

Electronic Frontiers Australia (2000c) Submission to the Senate Legal and Constitutional Legislation Committee: The Provisions of the Classification(Publications, Films and Computer Games) Amendment Bill (No. 2) http://www.efa.org.au/Publish/senate00.htm date accessed 6 May 2000. 
Electronic Frontiers Australia (1999) The Net Censorship Dilemma: Blinded by the Smoke - The Hidden Agenda of the Online Services Bill 1999. http://rene.efa.org.au/liberty/blinded.html date accessed 17 April 1999.

Flood M and Hamilton C (2003) Regulating Youth Access to Pornography, The Australia Institute Discussion Paper Number 53, March.

Forbes M (1999) Porn Sites Head Offshore to Beat Law Sydney Morning Herald 9 June.

Jackson D (2000) ABA accused of net cover-up AustralianIT 30 May.

McAuliffe M (2001) Oz Home Internet Subscribers Drop ZDNet Australia 1 May.

Office of Film and Literature Classification (1999a) Guidelines for the Classification of Computer Games: Amendment No. 1.

Office of Film and Literature Classification (1999b) Guidelines for the Classification of Films and Videotapes: Amendment No. 2.

Sandy G (2001) The Online Services Bill: Theories and Evidence of Pornographic Harm. Proceedings of the Second International Conference of the Australian Institute of Computer Ethics, 11-12 November 2000, Australian National University, Canberra.

Taggart S (2002) Oz Censor Law Still Confuses Wired News, 2 February. 